\title{
Current practices, attitudes, and perceived barriers for treating smokers by Hong Kong dentists
}

\author{
Kenneth WK Li *, David VK Chao
}

\section{A B S T R A C T}

Objectives: To assess the attitudes of dentists towards smoking cessation advice, as well as to investigate their current practice and perceived barriers to giving such advice and the relationships among their peers regarding such activity.

Design: Cross-sectional survey.

Setting: Hong Kong.

Participants: Self-reporting questionnaires were mailed to 330 dentists in Hong Kong by systematic sampling. Information on their attitudes, practices, and perceived barriers towards smoking cessation advice and relevant background information was collected.

Results: A total of 218 questionnaires were returned (response rate, 66\%). The majority (97\%) reported that they would enquire into every patient's smoking status, yet only around half of them did so routinely. Most (95\%) of the dentists who always enquired about smoking status would actually offer smoking cessation advice to their patients. Multiple logistic regression of the results revealed that government dentists (odds ratio $=2.7 ; 95 \%$ confidence interval, 1.4-5.1), those who received training in smoking cessation advice $(2.5 ; 1.2-5.1)$, and those aged over 40 years $(1.9 ; 1.0-3.4)$ were significantly more likely to enquire about smoking status. In most practices (93\%), smoking cessation advice was offered by the dentists themselves rather than by other team members. "Lack of training", "unlikely to be successful", and "possibility of losing patients" were the three barriers regarded as "very important" by dentists.

Conclusions: Dentists in Hong Kong generally had positive attitudes towards smoking cessation advice. The dental team is in a very good position to help smokers quit. However, training and guidelines designed specifically for dental teams are paramount to overcome barriers in delivering smoking cessation advice by dental professionals.

\section{Hong Kong Med J 2014;20:94-101}

DOI: $10.12809 / \mathrm{hkmj} 134027$

${ }^{1} \mathrm{KWK} \mathrm{Li}{ }^{*}$, BDS

${ }^{2}$ DVK Chao, FRCGP, FHKAM (Family Medicine)

Tai Po Wong Siu Ching Government Dental Clinic, 1 Po Wu Lane, Tai Po, Hong Kong

2 Department of Family Medicine and Primary Health Care, United Christian Hospital, Kwun Tong, Hong Kong

*Corresponding author: wkk_li@yahoo.com.hk

\section{New knowledge added by this study}

- The information gathered generally revealed a positive attitude towards delivering smoking cessation advice to smokers. However, lack of training and guidelines prevented dentists from implementing such advice in practice.

Implications for clinical practice or policy

- This study raises the awareness of dentists about delivering smoking cessation advice to patients in their daily practice.

- There is a need of specific guidelines for dentists to achieve this goal.

- Practical training on such activity should be encouraged and included in both the undergraduate and postgraduate training of dentists.

\section{Introduction}

Tobacco smoking is one of the most significant public health problems worldwide. The adverse effects of smoking on health are well known. ${ }^{1}$ According to the World Health Organization (WHO), the annual death toll could rise to more than eight million by 2030 , unless urgent action is taken against smoking. ${ }^{2}$
15 years or above are daily smokers. Men are the high-risk group and have a $22 \%$ prevalence of being smokers, which is much higher than in women $(4 \%) .^{3}$ The situation is particularly alarming, as the smoking population is becoming younger. ${ }^{3}$ Smoking contributes a large public health and medical burden to society.

The Hong Kong SAR Government has 
implemented numerous policies and enacted legislation on many occasions to combat tobacco smoking. Such action has entailed raising tobacco tax, making amendments to the existing Smoking (Public Health) Ordinance to prohibit smoking in public places, restricting the sale of tobacco products and tobacco advertising. While strategies such as taxation and prohibition of advertising are proven to be effective, one effective strategy that should not be ignored is "smoking cessation advice" (SCA) delivered by health care professionals.

Smoking tobacco has been identified as an important cause of various oral diseases and pathologies. It is one of the most important factors predisposing to pre-cancerous lesions and cancer of the oral cavity, the reported pooled cancer risk being 3.4-fold higher than in non-smokers. ${ }^{4}$ It also increases the risk of periodontal diseases, ${ }^{5}$ complications after extractions, ${ }^{6}$ and increased rates of implant failures. ${ }^{7}$ Cross-sectional studies show that smokers have more tooth loss. ${ }^{8}$ Other easily recognised effects include staining of teeth, ${ }^{9}$ dental restorations, and prosthesis $^{10}$ as well as alteration of taste perception ${ }^{11}$ and halitosis. ${ }^{12}$ All these have detrimental effects on the quality of life of smokers because of reduced chewing efficiency, poor aesthetics, and poor selfesteem. ${ }^{13}$

The benefits of smoking cessation are substantial. Evidence shows that smoking counselling given by dental professions can be effective and comparable to that offered by other primary care professionals. ${ }^{14-16}$ Around a quarter of the population have regular dental checkups and $53 \%$ have their teeth checked every 1 or 2 years. ${ }^{17}$ In their daily practice, dental professionals have access to a large patient population, including smokers. Besides, the detrimental effects of smoking on the oral cavity can be readily demonstrated directly and thus easily appreciated by patients; this acts as a strong motivator to quit smoking. ${ }^{16}$ Moreover, dental treatments entailing multiple visits provide good opportunities to motivate, reinforce, and support smoking cessation. Thus, dental professionals are in an excellent position for delivering advice and counselling to smokers. Notably, counselling by dentists has been reported to achieve an $8.6 \%$ cessation rate after 1 year, and over $16 \%$ when also coupled with nicotine replacement therapies. ${ }^{18}$ Despite these observations, delivery of SCA by dentists remains less than satisfactory. ${ }^{19-22}$ According to the literature, the reported barriers to such activity include lack of time, resources, remuneration, training, and fear of damaging dentist-patient rapport. $^{23}$

In Hong Kong, a study conducted in 2006 showed that more than half of all medical doctors did not have adequate knowledge (53\%) or favourable attitudes (55\%) towards smoking cessation. ${ }^{24}$ Slightly

\section{香港牙醫對輔導戒煙的現行做法、態度和 遇到的障礙 \\ 李穎傑、周偉強}

目的：評估牙醫對於提供協助戒煙指引的態度, 探討他們現行的做法 和遇到的障礙, 以及研究他們在提供協助戒煙指引時與同行之間的關 係。

設計：橫斷面調查。

安排：香港。

參與者：利用系統抽樣方法把自我填寫的問卷郵寄給330名香港牙 醫。問卷收集的資料包括他們對於提供協助戒煙指引的態度、行為和 遇到的障礙, 以及受訪者的相關背景資料。

結果：共收回問卷218份（回應率為66\%）。大部分受訪牙醫（97\%） 表示他們會詢問病人的吸煙狀況, 但只有約一半將這當作常規。經常 詢問病人吸煙狀況的受訪牙醫中, 大部分 $(95 \%)$ 會提供協助戒煙指 引。多因素邏輯回歸分析顯示政府牙醫（比值比 $=2.7 ； 95 \%$ 置信區間 為1.4-5.1 ) 、曾接受協助戒煙培訓（2.5；1.2-5.1），以及年齡超過 40 歲的牙醫（1.9；1.0-3.4) 有顯著較大機會詢問病人的吸煙狀況。 大多數情況下 $(93 \%)$ 是由牙醫自己提供協助戒煙指引, 而非由其他 團隊成員提供。「缺乏培訓」、「對於成功提供協助戒煙指引的信心 不足」、和「恐怕病人會因此不再求診」是受訪牙醫認為過程中非常 重要的三大障礙。

結論：香港牙醫普遍對提供協助戒煙指引持正面態度。牙科團隊在戒 煙輔導的角色扮演上相當有利。然而, 必須為他們進行專門為牙科團 隊設計的培訓和指引, 以克服可能遇到的障礙。

over $40 \%$ lacked confidence in delivery of SCA. Although $77 \%$ of them obtained information on the smoking status of their patients, only $29 \%$ advised them to quit smoking, reflecting a low involvement of medical doctors in the promotion of smoking cessation. $^{24}$

Local published data on the dentists' attitudes, practices, and barriers to delivering SCA to patients are limited, except for one study by Lu et al. $^{25}$ The rationale of the present study was to collect data from local dentists, and compare local results with those gleaned from international studies.

The objectives of the present study were: (1) to assess the attitudes of dentists towards SCA; (2) to investigate the current practice of dentists in respect of SCA; (3) to examine the perceived barriers to offering SCA; and (4) to seek possible relationships between the characteristics of dentists and their SCA activity.

\section{Methods}

A 17-item structured, self-administered and validated questionnaire developed by Stacey et $\mathrm{al}^{26}$ in 2006 in the UK was adopted as the survey instrument. The questionnaire consisted of three main parts: (1) smoking cessation views and activities of the dental team; (2) perceived barriers 
to giving SCA; and (3) perception of the importance of the smoking cessation role of the dental team and general medical practitioners. It was pilot-tested with a small convenience sample $(n=20)$ of dentists.

The target population consisted of 2026 general dentists registered with the Hong Kong Dental Council, whose correspondence addresses are available on a website ${ }^{27}$ that is open to the general public. The inclusion criterion was any dentist who was currently having a dental practice in Hong Kong with a valid address at the time of this survey. A systematic sample (every 6 th dentists on the list) was drawn from the 2026 registered general dentists in Hong Kong, so as to yield the desired sample size. A sample size of 324 subjects was calculated as needed based on a $5 \%$ margin of error (type I error), and 95\% confidence level, assuming 50\% response after distribution. Thus, 330 questionnaires were mailed in January 2012 with stamped self-addressed reply envelopes. Other means of reply allowed were by fax or by online completion of the questionnaires via a designated website. Another follow-up round of 330 questionnaires was sent to these dentists again 3 weeks after the first mailing.

\section{Data analysis}

A pilot study was carried out with a convenience sample $(n=20)$ to ensure the face validity of the questionnaire. Test-retest reliability test was also performed using these 20 subjects who were asked to complete the questionnaire a second time (2 weeks later). The questionnaire was viewed by three experts in dental public health to ensure its suitability for the present study.

All data were analysed with the Statistical Package for the Social Sciences (Windows version 19.0; SPSS Inc, Chicago [IL], US). Frequency distributions were generated to illustrate the demographic data, their attitudes, practices, and perceived barriers in SCA. To examine any relationships between demographic variables and outcomes, unconditional logistic regression analysis was performed with each demographic variable and the outcome variables (attitudes, practices, perceived barriers). Multiple logistic regression was then performed for variables that yielded a $P$ value of $<0.25$ in the individual analysis. The final model contained those statistically significant variables, using a stepwise-forward Wald logistic regression. The significance level was set at 0.05 .

\section{Results}

\section{Response rate and demographic backgrounds}

From the 330 selected dentists, 223 questionnaires were returned ( 163 by mail, 39 by fax, 21 online), of which five were incomplete. Thus, 218 questionnaires were valid for analysis, yielding a response rate of
$66 \%$. Alarmingly, less than one fourth of the dentists had received training in SCA. Only $16 \%$ of them had received such training during their undergraduate training and only $12 \%$ during postgraduate training. Moreover, only approximately $60 \%$ of the dentists claimed that they knew the contact of relevant supporting agencies for SCA. Table 1 shows the background of these dentists.

\section{Current practices on smoking cessation}

Nearly $97 \%$ of the dentists claimed that they would enquire about their patients' smoking status, yet only around half of them would always do so as a routine (Fig 1). About 97\% would enquire about smoking status whenever a patient presented with oral diseases related to smoking (eg periodontal disease and leukoplakia). The percentage of routine enquiries about smoking status when patients presented with oral white lesion (a symptom of oral pre-cancer) was slightly higher (73\%) than those presented with periodontal disease (66\%).

For dentists who would not routinely enquire about the smoking status, around half (53\%) would always do so when patients presented with an oral white lesion, and around $40 \%$ would do so when the latter presented with periodontal disease.

TABLE I. Demographic background of the dentists $(n=2 \mid 8)$

\begin{tabular}{|cc}
\hline Background information & No. (\%) \\
\hline Gender & $123(56)$ \\
\hline Male & $95(44)$ \\
\hline Agemale & \\
$\quad \leq 30$ & $79(36)$ \\
\hline $31-40$ & $58(27)$ \\
\hline$>40$ & $81(37)$ \\
\hline Years of practice (years) & \\
\hline$<10$ & $101(46)$ \\
\hline $10-20$ & $54(25)$ \\
\hline$>20$ & $63(29)$ \\
\hline Type of practice & \\
\hline Government & $74(34)$ \\
\hline University or institutions & $128(59)$ \\
\hline Private & $16(7)$ \\
\hline Training in SCA & \\
\hline Yes & $54(25)$ \\
\hline No & $164(75)$ \\
\hline Smoke or not & $5(2)$ \\
\hline Yes & $209(96)$ \\
\hline No & $4(2)$ \\
\hline Ex-smoker & \\
\hline
\end{tabular}

Abbreviation: SCA = smoking cessation advice 
For dentists who would always enquire about smoking status, $95 \%$ claimed they actually offered SCA. The majority of the dental practices (93\%) entailed SCA offered by the dentists themselves, only $16 \%$ had dental nurses/hygienists who offered

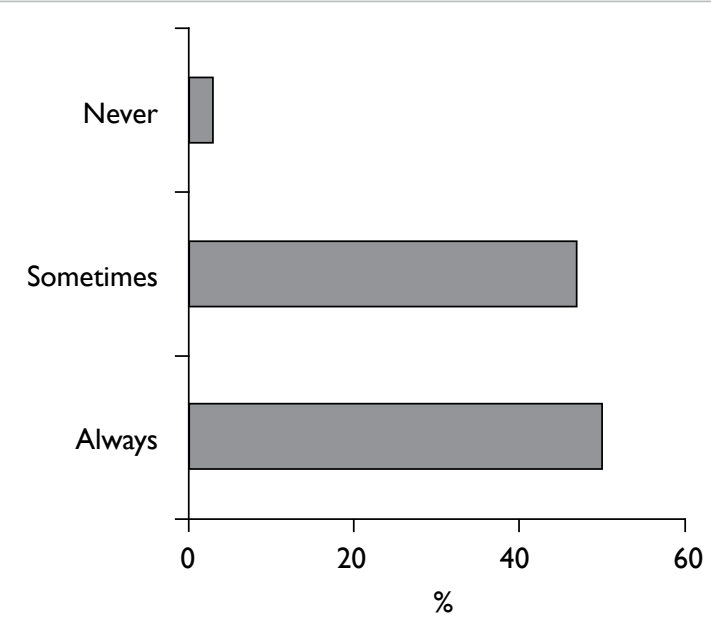

FIG. I Proportion of dentists who enquired about patient's smoking status such advice and only 3\% had practice managers/ receptionists who did so.

After adjustments and exclusion of nonsignificant variables in the unconditional logistic regressions, only three variables were retained in the final model and were found to be statistically significant. These were the type of practice, receipt of training in SCA, and age. Government dentists, those who had received training in SCA, and those aged over 40 years were more likely to always enquire about their patients' smoking status (outcome variable of the model, $\mathrm{P}<0.05$; Table 2 ).

Trained dentists were more likely to always enquire about smoking when patients presented with periodontal disease than non-trained dentists, the respective odds ratio (OR) and $95 \%$ confidence interval (CI) being 3.3 and 1.5-7.2. Government dentists were also more likely to enquire about smoking when patients presented with a white oral lesion (OR=2.9; 95\% CI, 1.4-6.1).

Similar results prevailed with respect to actually offering SCA to patients. Government dentists offered such advice more often than nongovernment dentists according to the logistic regression analysis $(\mathrm{OR}=8.3$; 95\% CI, 1.1-64.4).

Moreover, government dentists were more

TABLE 2. Relationships between dentists who always enquire about patient's smoking status and their demographic backgrounds (univariate and multiple logistic regression)

\begin{tabular}{|c|c|c|c|c|c|}
\hline \multirow[t]{2}{*}{ Variable } & \multirow{2}{*}{$\begin{array}{l}\text { No. }(\%) \text { who always enquire } \\
\text { patient's smoking status }\end{array}$} & \multicolumn{2}{|c|}{ Unconditional logistic regression } & \multicolumn{2}{|c|}{ Multiple logistic regression } \\
\hline & & OR $(95 \% \mathrm{Cl})$ & $P$ value & OR (95\% Cl) & $P$ value \\
\hline \multicolumn{6}{|l|}{ Type of practice ${ }^{\star}$} \\
\hline Government & $50(68)$ & $3.1(1.7-5.6)$ & $<0.001$ & $2.7(1.4-5.1)$ & 0.003 \\
\hline Non-government & $58(40)$ & 1 (reference) & & 1 (reference) & \\
\hline \multicolumn{6}{|l|}{ Training in $\mathrm{SCA}^{*}$} \\
\hline Yes & $39(72)$ & $3.6(1.8-7.0)$ & $<0.001$ & $2.5(1.2-5.1)$ & 0.012 \\
\hline No & $69(42)$ & 1 (reference) & & 1 (reference) & \\
\hline \multicolumn{6}{|l|}{$\mathrm{Age}^{\star}$} \\
\hline$>40$ Years & $47(58)$ & $1.7(1.0-3.0)$ & $<0.05$ & $1.9(1.0-3.4)$ & 0.040 \\
\hline$\leq 40$ Years & $61(45)$ & 1 (reference) & & 1 (reference) & \\
\hline \multicolumn{6}{|l|}{ Years of practice } \\
\hline$>20$ Years & $35(56)$ & $1.4(0.8-2.5)$ & 0.23 & & \\
\hline$\leq 20$ Years & $73(47)$ & 1 (reference) & & & \\
\hline \multicolumn{6}{|l|}{ Smoking status } \\
\hline No & $106(50)$ & $1.5(0.2-9.1)$ & 0.67 & & \\
\hline Yes & $2(40)$ & 1 (reference) & & & \\
\hline \multicolumn{6}{|l|}{ Gender } \\
\hline Female & $50(53)$ & $1.2(0.7-2.1)$ & 0.42 & & \\
\hline Male & $58(47)$ & 1 (reference) & & & \\
\hline
\end{tabular}

Abbreviations: $\mathrm{Cl}=$ confidence interval; $\mathrm{OR}=$ odds ratio; $\mathrm{SCA}=$ smoking cessation advice

* Variables with significant $\mathrm{P}$ value or $<0.25$ in the unconditional logistic regressions being included into multiple logistic regression so as to yield the final model 


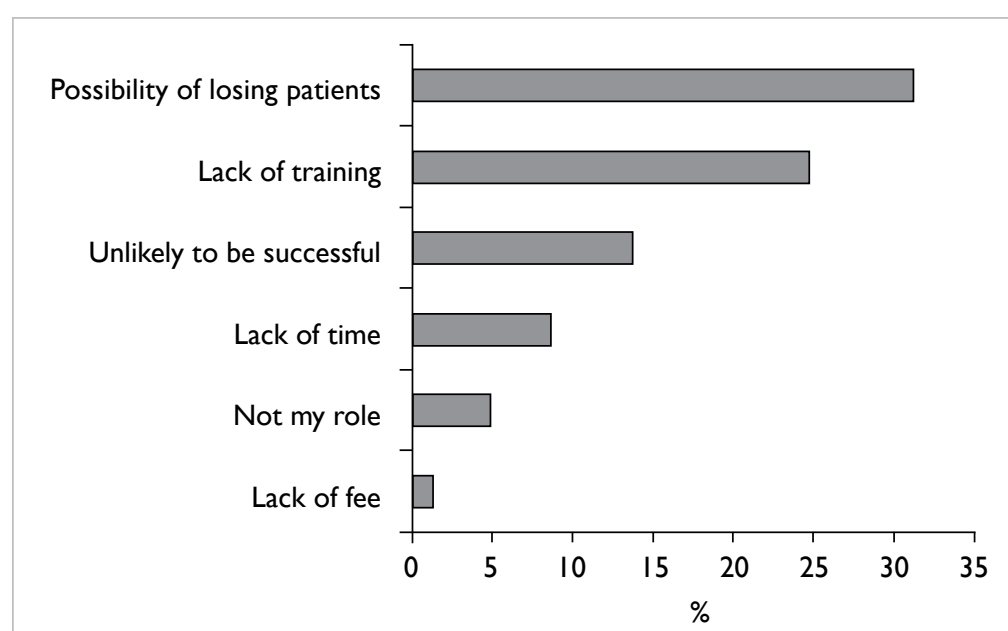

FIG. 2 Proportion of each barrier being regarded as "very important" by the dentists $(n=2 \mid 8)$ important (Fig 2).

\section{Discussion}

This study gathered information on the current attitudes, practices, and perceived barriers among dentists in delivering SCA to Hong Kong patients, which could have implications for the development of training programmes and provide directions for future research.

\section{Knowledge and attitudes towards smoking cessation advice}

The present study showed that Hong Kong dentists generally had positive attitudes and knowledge about SCA, and recognised the adverse effects of smoking on oral health, as reflected by the high percentages for enquiry about a patient's smoking status. Moreover, nearly $90 \%$ expressed positive attitudes towards SCA, in that they agreed it had an important role to play.

likely to know how to contact supporting agencies $(\mathrm{OR}=2.3 ; 95 \% \mathrm{CI}, 1.1-4.6)$ than non-government counterparts, and trained dentists were more likely to know how to contact supporting agencies (OR=14.3; 95\% CI, 4.2-48.5) than those non-trained.

\section{Attitudes and perceptions of dentists on the role of delivering smoking cessation advice}

A high proportion (89\%) of dentists agreed or strongly agreed that the dental team has an important role in delivering SCA to patients; the percentage who agreed or strongly agreed that medical doctors had an important role was slightly higher (93\%).

Trained dentists were 8.5 times more likely to think that it was imperative for dental teams to offer SCA $(\mathrm{P}<0.05)$. Almost all $(98 \%)$ of those who received training thought that dentists should offer SCA, which was more than that for those who did not have such training ( $86 \% ; \mathrm{P}=0.014)$.

When dentists were asked who should offer SCA in the team, most (approximately 90\%) claimed that they should be responsible, whilst $41 \%$ thought that nurses should also be involved, and $47 \%$ felt that hygienists too should be involved. However, only $16 \%$ of such personnel were actively involved in offering SCA; the percentages were even lower for receptionists (3\%) and practice managers (1\%).

\section{Perceived barriers to delivering smoking cessation advice by dentists}

Among the potential barriers listed in the questionnaire, the most important one identified by the dentists was the "possibility of losing patients" (31\%), followed by the "lack of training" (25\%) and the "unlikely to be successful" (14\%). On the other hand, the "lack of time", the "lack of fee", and the "not perceived as my role" were not regarded as

\section{Training and guidelines are important but inadequate}

Government dentists and dentists who received training were significantly more likely (approximately 3 times) to routinely enquire about a patient's smoking status than other dentists. Trained dentists were also approximately 14 times more likely to know how to contact local supporting agencies, and more than 8 times as likely to offer SCA to the patients. They also perceived their role in offering SCA as very important and were more actively involved than other team members in its delivery. These results were similar to those for Hong Kong medical doctors ${ }^{24}$ as well as findings of other international and local studies. ${ }^{20-22,25}$

This study reflects the importance of training and guidelines, although these were not widely available. Only a small proportion (16\%) of dentists received training in SCA during their undergraduate studies. Notably, for local students the limited practical training in essential techniques for delivering SCA to patients was similar to the situation in the United States and Europe. ${ }^{28,29}$ Research has shown that to increase the effectiveness of SCA, education is needed to expand both didactic knowledge and clinical competencies to help patients quit smoking. ${ }^{30}$ Evidence also suggests that training should be provided early and continued throughout subsequent courses. ${ }^{31}$ Inclusion of both theoretical and practical training (counselling skills, problemsolving strategies) should be considered in future undergraduate curricula. Moreover, continuing professional education programmes focusing on hands-on SCA techniques could help dentists acquire better knowledge and more up-to-date techniques. According to the results, the continuing 
education programmes should be directed towards younger and non-government dentists.

The Department of Health has guidelines on SCA for the government dental officers, which includes annual updating of the patient's smoking status, provision of SCA, and obtaining patient consent for referral to Tobacco Control Office when needed. This may be one reason government dentists were more likely to enquire about a patient's smoking status, offer SCA, and confirm the importance of relevant guidelines. As in other countries, many dentists are not familiar with guidelines like the " $5 \mathrm{~A}$ approach". ${ }^{2}$ Evidence suggests that dentists familiar with guidelines are more likely to engage in SCA. ${ }^{33}$ Local information and guidelines on SCA are mostly unclear, as they were not being designed specifically for dentists and may not be readily accessible to them. ${ }^{34}$ Not surprisingly, only approximately $60 \%$ of the dentists knew how to contact supporting agencies. Thus, clear, evidence-based, and easily accessible guidelines designed for the dental profession should be developed to facilitate the effective delivery of SCA by dental professionals.

Recently, a WHO Collaborating Centre for Smoking Cessation and Treatment of Tobacco Dependence was set up by Department of Health. It aims to provide evidence-based smoking cessation training for health care personnel. It also aims to develop, test, and evaluate models of smoking cessation to support WHO's initiatives on assistance in the dissemination of relevant information on smoking cessation. Hopefully therefore, the dental profession will have more opportunities to receive training in SCA in the near future. ${ }^{35}$

\section{Barriers}

Despite their apparently positive attitudes to SCA, only around half of the dentists always enquired about each patient's smoking status and, if indicated, offered SCA. These findings are consistent with those from Australia ${ }^{36}$ and for Hong Kong medical doctors. ${ }^{24}$ The difference in the beliefs and the actual practice of dentists suggest barriers to implementation. In the present study, "lack of training", "possibility of losing patients", and "unlikely to be successful" were regarded as important barriers by the dentists, and were similar to those reported in the $\mathrm{UK}^{26}$ and Malaysia. ${ }^{20}$ They suggest that dentists lack confidence in delivering SCA and reinforce the importance of adequate training. Dentists worry that by offering SCA, they might damage relationships with their patients. However, in reality, research indicates that over half of the patients expect their dentists to discuss issues related to smoking. ${ }^{37}$ Also, such discussion could cultivate rapport between the dentists and the patients. Thus, actually delivering SCA could be very cost-effective in terms of gaining patient trust. To encourage involvement of dentists in delivering SCA, efforts should be directed at reducing the above-mentioned barriers (provision of adequate training, informing the dentists about current evidence, reducing their worries about damaging relationships with patients).

\section{Team approach}

In this study, over $40 \%$ of the dentists expressed that other personnel in their teams (nurses, hygienists) should be involved in delivering SCA, though the percentages were lower than those in the UK. ${ }^{26}$ Thus, dentists generally recognised the importance of the team approach to delivering SCA, and the literature indicates that such team members (including administrative staff) are in a good position to do so. ${ }^{18,38}$ This is especially true for the hygienists, who are responsible for managing periodontal diseases that are smoking-related and require multiple visits, and therefore offer excellent opportunities to deliver SCA. ${ }^{39,40}$

The team approach should be encouraged, and as team leader, the dentist has overall responsibility and should actively involve other staff. ${ }^{41}$ In order to increase the effectiveness, training of the entire dental office team could be considered. ${ }^{42}$ The proportion of local dentists who thought practice managers and receptionists should be involved was low compared to that reported from the UK. ${ }^{26}$ Variations in dental clinic organisation in different countries may be part of the reason; for example, locally it is not common to involve dental practice managers in patient care.

\section{Comparison with other studies}

As mentioned previously, various aspects of our results were generally comparable to those of other studies. The response rate in the present study was just under $70 \%$, which was higher than $60 \%$ reported from the UK, ${ }^{26}$ and $55 \%$ reported from Malaysia, ${ }^{20}$ as well as $19 \%$ reported for Hong Kong medical doctors ${ }^{24}$ and $50 \%$ in another study on Hong Kong dentists. ${ }^{25}$ Our higher questionnaire response rate could be because the questions were simple, straightforward, and not time-consuming. Notably, the locally developed questionnaire used by $\mathrm{Lu}$ et $\mathrm{al}^{25}$ (on Hong Kong dentists) gathered more detailed information than we did.

\section{Limitations}

The relatively low response rate in our study may limit the generalisability of the results, and our sample size was less than ideal. A full population survey should be conducted if resources and time permit. The tendency of respondents to provide positive, favourable responses may be a source of bias, resulting in an over-optimistic estimate of SCA implementation. The characteristics of the nonrespondents were not known due to the anonymous 
nature of the questionnaire. The questionnaire was comparatively simple, and did not address specific aspects of knowledge on SCA, nor any specific aspects of advice offered to patients. This limited the scope of information being collected. Due to time and resource limitations, other important personnel, such as nurses and hygienists, were not surveyed.

\section{Recommendations for future researches}

A qualitative design could be considered to gain a deeper understanding on the beliefs and barriers to SCA with respect to the dental professions. Thereafter an updated questionnaire could be designed and validated, specifically for the local setting. This could entail specific questions on the knowledge of dentists regarding SCA and the specific activities they and their teams undertake. Further research could also focus on evaluating the effectiveness of different smoking cessation training programmes and practical approaches to SCA.

\section{Conclusions}

The present research showed that dentists in Hong Kong generally have positive attitudes towards their role in delivering SCA to patients. However, barriers like the relative lack of training and guidelines, the lack of confidence, and fear of damaging relationships with patients may prevent them from delivering the relevant advice. Local guidelines specifically designed for the dental profession should be developed and relevant resources made readily accessible. More importantly, adequate practical training programmes should be included in both the undergraduate curriculum and continuing education activities, especially for the private and younger dentists.

\section{References}

1. World Health Organization. WHO report on the global tobacco epidemic, 2011: Warning about the dangers of tobacco. Geneva: WHO; 2011.

2. WHO key facts about tobacco. Available from: http://www. who.int/mediacentre/factsheets/fs339/en. Accessed 29 Apr 2012.

3. Census and Statistics Department, Hong Kong. General household survey and thematic household survey, 2011. Available from: http://www.census2011.gov.hk/en/index. html. Accessed Feb 2014.

4. Gandini S, Botteri E, Iodice S, et al. Tobacco smoking and cancer: a meta-analysis. Int J Cancer 2008;122:155-64.

5. Bergstrom J. Periodontitis and smoking: an evidence-based appraisal. J Evid Based Dent Pract 2006;6:33-41.

6. Johnson NW, Bain CA. Tobacco and oral disease. EUWorking Group on Tobacco and Oral Health. Br Dent J 2000;189:200-6.

7. Reibel J. Tobacco and oral diseases. Update on the evidence, with recommendations. Med Princ Pract 2003;12 Suppl 1:22-32.

8. Ylöstalo P, Sakki T, Laitinen J, Järvelin MR, Knuuttila M.
The relation of tobacco smoking to tooth loss among young adults. Eur J Oral Sci 2004;112:121-6.

9. Eriksen HM, Nordbo H. Extrinsic discoloration of teeth. J Clin Periodontol 1978;5:229-36.

10. Asmuseen E, Hansen EK. Surface discoloration of restorative resins in relation to surface softening and oral hygiene. Scan J Dent Res 1986;94:174-7.

11. Pasquali B. Menstural phase, history of smoking and taste discrimination in young women. Percept Mot Skills 1997;84:1243-6.

12. Rosenberg M. Clinical assessment of bad breath: current concepts. J Am Dent Assoc 1996;127:475-82.

13. Gerritsen AE, Allen PF, Witter DJ, Bronkhorst EM, Creugers NH. Tooth loss and oral health-related quality of life: a systematic review and meta-analysis. Health Qual Life Outcomes 2010;8:126.

14. Needleman IG, Binnie VI, Ainamo A, et al. Improving the effectiveness of tobacco use cessation (TUC). Int Dent J 2010;60:50-9.

15. John J. Tobacco smoking cessation counseling interventions delivered by dental professionals may be effective in helping tobacco users to quit. Evid Based Dent 2006;7:40-1.

16. Warnakulasuriya S. Effectiveness of tobacco counseling in the dental office. J Dent Educ 2002;66:1079-87.

17. Census and Statistics Department, Hong Kong. General household survey and thematic household survey, report no. 45. Available from: http://smokefree.hk/UserFiles/ resources/smoking_risk_cessation/thematic_household_ surveys/THS_45Report.pdf. Accessed Feb 2014.

18. Cohen SJ, Stookey GK, Katz BP, Drook CA, Christen AG. Helping smokers quit: a randomized controlled trial with private practice dentists. J Am Dent Assoc 1989;118:41-5.

19. Allard RH. Tobacco and oral health: attitudes and opinions of European dentists; a report of the EU working group on tobacco and oral health. Int Dent J 2000;50:99-102.

20. Ibrahim H, Norkhafizah S. Attitudes and practices in smoking cessation counselling among dentists in Kelantan. Archives of Orofacial Sciences 2008;3:11-6.

21. Uti OG, Sofola OO. Smoking cessation counseling in dentistry: attitudes of Nigerian dentists and dental students. J Dent Edu 2010;75:406-12.

22. Victoroff KZ, Dankulich-Huryn T, Haque S. Attitudes of incoming dental students toward tobacco cessation promotion in the dental setting. J Dent Educ 2004;5:563-8.

23. Watt RG, McGlone P, Dykes J, Smith M. Barriers limiting dentists' active involvement in smoking cessation. Oral Health Prev Dent 2004;2:95-102.

24. Abdullah AS, Rahman AS, Suen CW, et al. Investigation of Hong Kong doctors' current knowledge, beliefs, attitudes, confidence and practices: implications for the treatment of tobacco dependency. J Chin Med Assoc 2006;69:461-71.

25. Lu HX, Wong MC, Chan KF, et al. Perspectives of the dentists on smoking cessation in Hong Kong. Hong Kong Dent J 2011;8:79-86.

26. Stacey F, Heasman PA, Heasman L, Hepburn S, McCracken GI, Preshaw PM. Smoking cessation as a dental intervention-views of the profession. Br Dent J 2006;201:109-13.

27. The Hong Kong Dental Council. Lists of Registered Dentists in Hong Kong, September 2011. DCHK website: http://www.dchk.org.hk/docs/List_of_Registered_ Dentists_Local.pdf. Accessed 2 Jan 2012.

28. Geller AC, Powers CA. Teaching smoking cessation in U.S. medical schools: a long way to go. Virtual Mentor 
2007;9:21-5

29. Raupach T, Shahab L, Baetzing S, et al. Medical students lack basic knowledge about smoking: findings from two European medical schools. Nicotine Tob Res 2009;11:92-8.

30. Ramseier CA, Christen A, McGowan J, et al. Tobacco use prevention and cessation in dental and dental hygiene undergraduate education. Oral Health Prev Dent 2006;4:49-60.

31. Brown RL, Pfeifer JM, Gjerde CL, Seibert CS, Haq CL. Teaching patient-centered tobacco intervention to firstyear medical students. J Gen Intern Med 2004;19:534-9.

32. Succar CT, Hardigan PC, Fleisher JM, Godel JH. Survey of tobacco control among Florida dentists. J Community Health 2011;36:211-8.

33. $\mathrm{Hu} \mathrm{S}$, Pallonen U, McAlister AL, et al. Knowing how to help tobacco users. Dentists' familiarity and compliance with the clinical practice guideline. J Am Dent Assoc 2006;137:170-9.

34. Tobacco Control Office, Department of Health, Hong Kong. Health promotion-tobacco control resources centre. Available from: http//www.tco.gov.hk/English/health/ health_tcrc.html. Accessed 1 May 2012.

35. Hong Kong Council on Smoking and Health. News update - First WHO collaborating centre for smoking cessation officially launched in Hong Kong. COSH Website: http:// smokefree.hk/en/content/web.do?page=news20120410. Accessed 4 May 2012.

36. Trotter L, Worcester P. Training for dentists in smoking cessation intervention. Aus Dent J 2003;48:183-9.

37. Rikard-Bell G, Donnelly N, Ward J. Preventive dentistry: what do Australian patients endorse and recall of smoking cessation advice by their dentists? Br Dent J 2003;94:15964.

38. Pizzo G, Piscopo MR, Pizzo I, Giuliana G. Smoking cessation counselling and dental team [in Italian]. Ann Ig 2006;18:155-70.

39. Severson HH, Andres JA, Lichtenstein E, Gordon JS, Barckley MF. Using the hygiene visit to deliver a tobacco cessation program: results of a randomized clinical trial. J Am Dent Assoc 1998;129:993-9.

40. Stevens VJ, Severson H, Lichtenstein E, Little SJ, Leben J. Making the most of a teachable moment: a smokelesstobacco cessation intervention in the dental office. Am J Public Health 1995;85:231-5.

41. Campbell HS, Sletten M, Petty T. Patient perceptions of tobacco cessation advice in dental offices. J Am Dent Assoc 1999;130:219-26.

42. Wood GJ, Cecchini JJ, Nathason N, Hiroshige K. Office based training in tobacco cessation for dental professionals. J Am Dent Assoc 1997;128:216-24. 